\title{
Erratum to: On the relative strength of radiative feedbacks under climate variability and change
}

\author{
Robert Colman $^{1}$ (D) $\cdot$ Lawson Hanson $^{1}$
}

Published online: 7 April 2017

C) Springer-Verlag Berlin Heidelberg 2017

\section{Erratum to: Clim Dyn \\ DOI 10.1007/s00382-016-3441-8}

In the original publication of the article, Fig. 4 caption has been published incorrectly. The correct figure caption is given below:

The online version of the original article can be found under doi:10.1007/s00382-016-3441-8.

Robert Colman

r.colman@bom.gov.au

1 Australian Bureau of Meteorology, GPO Box 1289,

Melbourne, VIC 3001, Australia 

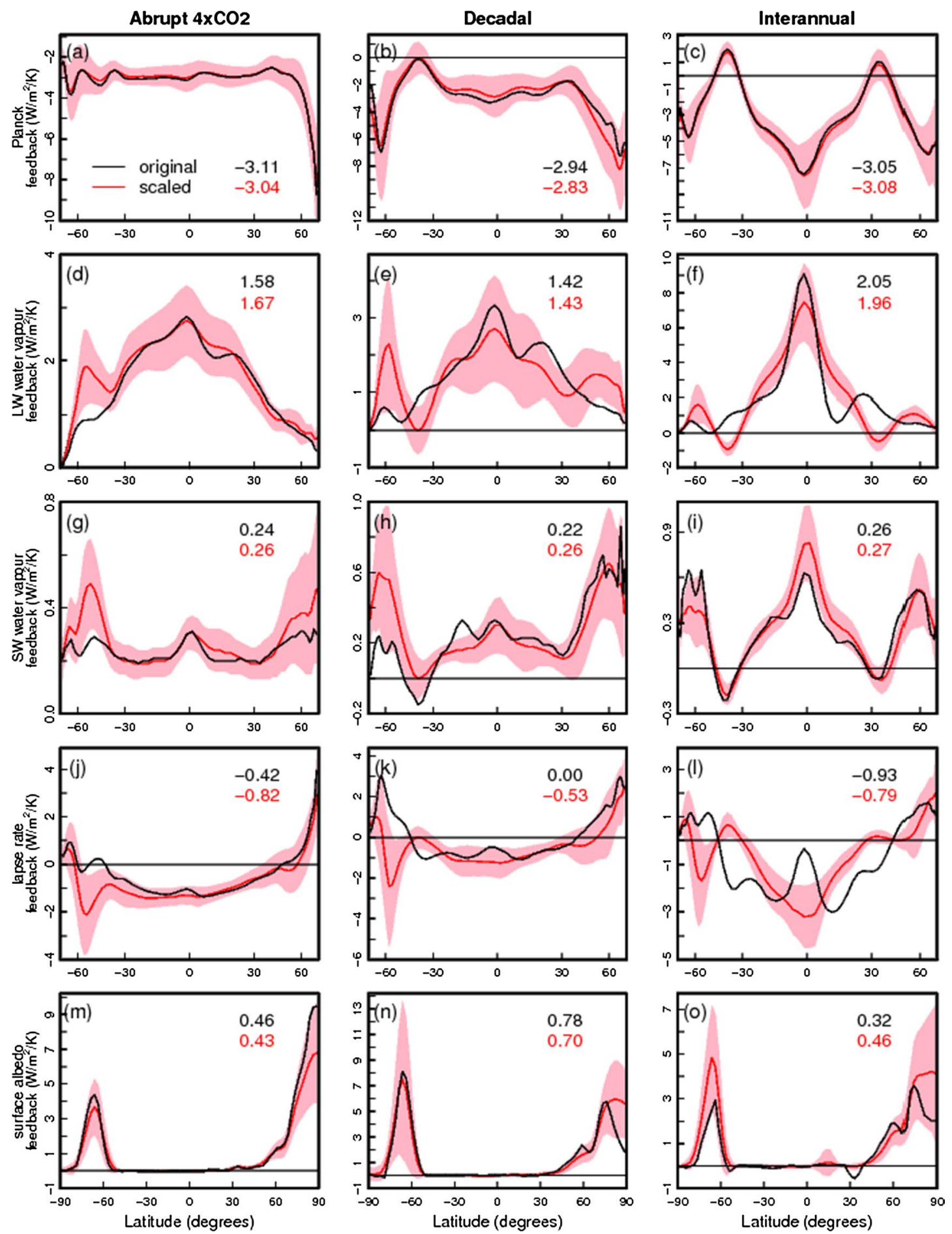

Fig. 4 Zonal mean climate feedbacks from the CMIP5 models for the Abrupt $4 \mathrm{xCO} 2$ (left) experiment and for decadal (centre) and interannual (right) variability in the pre-industrial experiment, as derived from RCP8.5 models regional feedbacks scaled by the appropriate regional to global temperature ratios (i.e. using Eq. 4). Red lines show the MMM of the 'synthetic' feedbacks, and the pink shading 1 standard deviation of model spread. The black line shows the MMM of the feedbacks calculated directly (i.e. by regres- sion for decadal and interannual variability, and by normalisation for abrupt $4 \mathrm{xCO} 2$ ). Shown are the Planck response ('feedback') and the water vapour (LW and SW), lapse rate and surface albedo feedbacks. All but the surface albedo feedbacks are shown as weighted by cosine (latitude) to display contribution to the global mean. Numbers in black and red show the MMM global feedbacks by the directly derived and 'synthetic' methods respectively. All units are $\mathrm{W} / \mathrm{m}^{2} / \mathrm{K}$ 